\title{
DREAM/calsenilin/KChIP3 modulates strategy selection and estradiol-dependent learning and memory
}

\author{
Tumay Tunur, ${ }^{1,3}$ Claire E. Stelly, ${ }^{2}$ and Laura Ann Schrader ${ }^{1,2,4}$ \\ ${ }^{1}$ Department of Cell and Molecular Biology, Tulane University, New Orleans, Louisiana 70118, USA; ${ }^{2}$ Program in Neuroscience, \\ Tulane University, New Orleans, Louisiana 70118, USA
}

\begin{abstract}
Downstream regulatory element antagonist modulator (DREAM)/calsenilin(C)/K+ channel interacting protein 3 (KChIP3) is a multifunctional $\mathrm{Ca}^{2+}$-binding protein highly expressed in the hippocampus that inhibits hippocampus-sensitive memory and synaptic plasticity in male mice. Initial studies in our lab suggested opposing effects of $D R / C / K 3$ expression in female mice. Fluctuating hormones that occur during the estrous cycle may affect these results. In this study, we hypothesized that $\mathrm{DR} / \mathrm{C} / \mathrm{K} 3$ interacts with $17 \beta$-estradiol, the primary estrogen produced by the ovaries, to play a role in hippocampus function. We investigated the role of estradiol and $\mathrm{DR} / \mathrm{C} / \mathrm{K} 3$ in learning strategy in ovariectomized (OVX) female mice. OVX WT and DR/C/K3 knockout (KO) mice were given three injections of vehicle (sesame oil) or 17 $\beta$-estradiol benzoate (0.25 $\mathrm{mg}$ in $100 \mathrm{~mL}$ sesame oil) 48, 24, and $2 \mathrm{~h}$ before training and testing. DR/C/K3 and estradiol had a time-dependent effect on strategy use in the female mice. Male KO mice exhibited enhanced place strategy relative to WT $24 \mathrm{~h}$ after pre-exposure. Fear memory formation was significantly reduced in intact female KO mice relative to intact WT mice, and OVX reduced fear memory formation in the WT, but had no effect in the KO mice. Long-term potentiation in hippocampus slices from female mice was enhanced by circulating ovarian hormones in both $\mathrm{WT}$ and $\mathrm{DR} / \mathrm{C} / \mathrm{K} 3 \mathrm{KO}$ mice. Paired-pulse depression was not affected by ovarian hormones but was reduced in $\mathrm{DR} / \mathrm{C} / \mathrm{K} 3 \mathrm{KO}$ mice. These results provide the first evidence that $\mathrm{DR} / \mathrm{C} / \mathrm{K} 3$ plays a timing-dependent role in estradiol regulation of learning, memory, and plasticity.
\end{abstract}

Downstream regulatory element antagonist modulator (DREAM)/ calsenilin $/ \mathrm{K}^{+}$channel interacting protein 3 (KChIP3) is a multifunctional $\mathrm{Ca}^{2+}$-binding protein that is highly expressed in the hippocampus, mainly in the dentate gyrus (Zaidi et al. 2002; Lilliehook et al. 2003). Several studies demonstrated that DREAM/calsenilin/KChIP3 (DR/C/K3) plays a role in hippocampus-sensitive memory and synaptic plasticity in male mice (Lilliehook et al. 2003; Alexander et al. 2009; Fontan-Lozano et al. 2009). Specifically, male DR/C/K3 knockout (KO) mice exhibited enhanced contextual fear memory (Alexander et al. 2009), object recognition, and conditioned taste aversion (Fontan-Lozano et al. 2009). In addition, slices from male KO mice showed enhanced long-term potentiation (LTP) at the CA3/CA1 synapses (Fontan-Lozano et al. 2009) and perforant path/dentate gyrus (PP-DG) synapses (Lilliehook et al. 2003). These results suggest that DR/C/K3 expression inhibits hippocampus-sensitive memory and synaptic plasticity in the hippocampus. Surprisingly, transgenic mice that express DREAM with mutated EF hands that lack the ability to bind $\mathrm{Ca}^{2+}$ showed impaired contextual fear conditioning and long-term depression (Wu et al. 2010). The opposing effects in the mice that lack DR/C/K3 and the mice that express the EF hand mutant suggest that DR/C/K3 has $\mathrm{Ca}^{2+}$-dependent and independent functions.

$\mathrm{DR} / \mathrm{C} / \mathrm{K} 3$ could contribute to these effects through potential divergent actions at the membrane and/or at the nucleus. As DREAM, it acts in the nucleus as a transcriptional regulator

\footnotetext{
3Present address: Department of Biology, Syracuse University, Syracuse, NY 13206, USA

Article is online at http://www.learnmem.org/cgi/doi/10.1101//m.032052.113.
}

(Carrion et al. 1999), and $\mathrm{Ca}^{2+}$-free DR/C/K3 is a transcriptional repressor that binds the downstream regulatory elements located in the promoter region of target genes (Carrion et al. 1999; Mellstrom and Naranjo 2001; Sanz et al. 2001; Savignac et al. 2005; Scsucova et al. 2005). At the membrane, it interacts with and increases surface expression of $\mathrm{Kv} 4 \mathrm{~K}^{+}$channel subunits (An et al. 2000) and decreases NMDAR currents (Zhang et al. 2010). As calsenilin it interacts with presenilin (Buxbaum et al. 1998), and a recent study shows that overexpression of DR/C/ $\mathrm{K} 3$ caused disruption of $\mathrm{N}$-cadherin cleavage by the presenilin1/ $\gamma$-secretase.

Since DR/C/K3 influences hippocampus function, DR/C/K3 expression could also regulate learning strategy in hippocampussensitive tasks. Investigation of learning strategy has been used to determine the participation of brain areas in spatial memory. Place strategy is an allocentric navigation strategy that depends on extramaze cues. Response strategy is an egocentric navigation strategy based on proprioceptive cues (White and McDonald 2002; Gold 2004; Mizumori et al. 2004). Place strategy is dependent on the hippocampus, while response strategy is dependent on the striatum. This is demonstrated by experiments that showed inactivation of the hippocampus-biased animals to response strategy use, and inactivation of the striatum-biased animals to place strategy use (Packard and McGaugh 1996; Lee et al. 2008). Furthermore, glutamate infusion into the hippocampus

\footnotetext{
(C) 2013 Tunur et al. This article is distributed exclusively by Cold Spring Harbor Laboratory Press for the first 12 months after the full-issue publication date (see http://learnmem.cshlp.org/site/misc/terms.xhtml). After 12 months, it is available under a Creative Commons License (AttributionNonCommercial 3.0 Unported), as described at http://creativecommons. org/licenses/by-nc/3.0/.
} 
strengthened place strategy use and, conversely, glutamate infusion into the striatum enhanced response strategy use (Packard 1999).

Although most studies that investigate DR/C/K3 and strategy selection study males, an important modulatory factor that could influence $\mathrm{DR} / \mathrm{C} / \mathrm{K} 3$ regulation of the hippocampus and learning strategies is $17 \beta$-estradiol, the primary estrogen produced by the ovaries. Estradiol rapidly enhances hippocampus-dependent memory (Daniel 2006; Luine 2008; Luine and Frankfurt 2012), most likely through estradiol's effects on neurogenesis (Ormerod et al. 2003; Mazzucco et al. 2006; Li et al. 2011), and synaptic and structural plasticity, including enhanced dendritic spine density in area CA1 pyramidal cells (Woolley and McEwen 1992; Rudick and Woolley 2001). It is also an important factor that is known to affect learning strategy in female rodents, enhancing the hippocampus-sensitive place strategy over striatumdependent response strategy (Korol and Kolo 2002; Daniel and Lee 2004; Korol et al. 2004; Davis et al. 2005; Tunur et al. 2010). We previously used a water plus-maze and context pre-exposure to demonstrate that male mice and intact female mice at proestrus predominantly used place strategy, suggesting enhanced hippocampus function. On the other hand, OVX female mice used response strategy, suggesting enhanced striatal function (Tunur et al. 2010). In the present study, we used water plus-maze to further dissect the role of DR/C/K3 and estradiol in the hippocampus. We used behavioral and electrophysiological techniques to test the hypothesis that DR/C/K3 plays a role in learning and memory formation and hippocampus function possibly through an interaction with $17 \beta$-estradiol functions.

\section{Results}

\section{K3/DR/C and estradiol regulate strategy selection}

In order to investigate an interaction of $\mathrm{DR} / \mathrm{C} / \mathrm{K} 3$ and estradiol in modulation of strategy selection of female mice following preexposure to the training and testing context in a dual-solution water plus-maze task, two different groups of female mice were trained and tested at two different time points after pre-exposure, immediately and $24 \mathrm{~h}$ after, to investigate the effect of preexposure at both short- and long-term latencies.

In the first strategy study, a total of $19 \mathrm{WT}$ and $24 \mathrm{DR} / \mathrm{C} / \mathrm{K} 3$ $\mathrm{KO}$ female mice were ovariectomized and divided randomly into groups based on drug treatment (WT Oil, WT E, KO Oil, KO E). All groups received assigned injections $(0.25 \mu \mathrm{g} 17 \beta$-estradiol benzoate, or sesame oil) for three consecutive mornings $(48,24$, and $2 \mathrm{~h}$ before training). On the last day of injection, mice were pre-exposed to the training and testing context for $5 \mathrm{~min}$. Ten (two WT Oil, one WT E, one KO Oil, and six KO E) of the 43 females were dropped from the study for failure to reach the minimum requirement to remain in the study (four correct out of nine trials), failure to escape to the platform due to floating, or aberrantly high anxiety levels as demonstrated by hyperactivity or vocalization. Estradiol treatment did not significantly affect the use of place strategy in WT animals when trained immediately after pre-exposure $\left(P>0.1, \chi^{2}=1.67\right.$, Chi square). One of seven WT oil-injected animals used place strategy, whereas four of nine of the WT estradiol-injected animals used place strategy. On the other hand, estradiol treatment significantly enhanced place strategy use in DR/C/K3 KO mice $\left(P<0.001, \chi^{2}=10.12\right.$, Chi square) (Fig. 1A). Although none of 10 oil-injected DR/C/K3 $\mathrm{KO}$ females used place strategy, five of seven estradiol-injected $\mathrm{DR} / \mathrm{C} / \mathrm{K} 3 \mathrm{KO}$ females used place strategy. Learning curves of the latency to find the platform during training trials revealed a significant effect of trial $\left(F_{(8,220)}=11.88, P<0.0001\right.$, nonrepeated measures two-way ANOVA), but not of hormone replacement or genotype $\left(F_{(3,220)}=0.55, P=0.65\right.$, nonrepeated measures twoway ANOVA) (Fig. 1B). These results suggest that short-term hippocampus-sensitive memory is enhanced by estradiol in $\mathrm{DR} / \mathrm{C} /$ $\mathrm{K} 3 \mathrm{KO}$ female mice.

For the second strategy study, $28 \mathrm{WT}$ and 27 DR/C/K3 KO female mice received the surgery and hormone treatments as explained above. We pre-exposed the females to the training and testing context $24 \mathrm{~h}$ before training and testing on the second day of injections and trained and tested them on the third day. Twenty (four WT Oil, six WT E, six KO Oil, and four KO E) of the 55 females were dropped from the study for failure to reach the minimum requirement to remain in the study (four correct

A Females immediate and 24 hours after pre-exposure

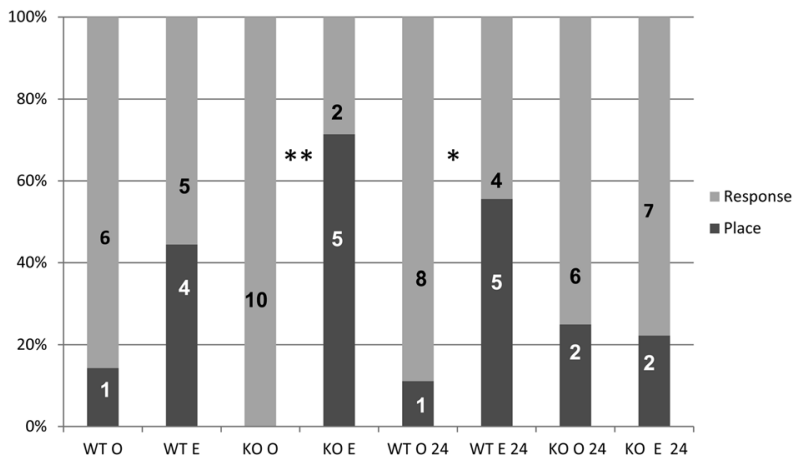

B

Latency Curves (immediate)

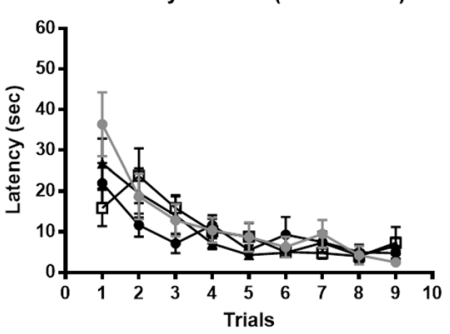

C

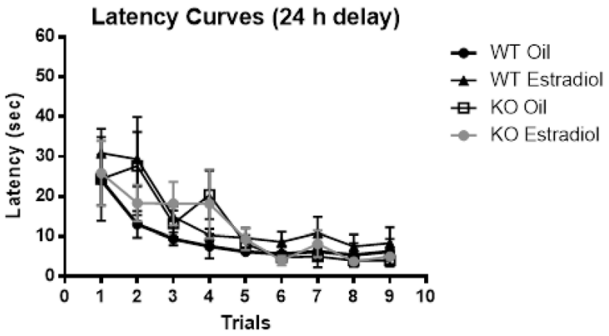

Figure 1. $D R / C / K 3$ inhibits estradiol-modulated place strategy use in water plus-maze task immediately after pre-exposure to training and testing context, but it enhances place strategy use $24 \mathrm{~h}$ after preexposure. Female mice were trained and tested on water plus-maze immediately or $24 \mathrm{~h}$ after the pre-exposure. (A) Bar graph showing the number of WT and DR/C/K3 knockout (KO) animals that utilized place versus response strategies. A significantly higher percentage of estradioltreated KO mice used place strategy compared to oil-treated KO mice $\left(\left[{ }^{* *}\right] P<0.001\right)$ when trained and tested immediately after pre-exposure. In addition, $24 \mathrm{~h}$ after context pre-exposure, estradiol-treated WT mice used place strategy significantly more than oil-treated WT mice at $24 \mathrm{~h}$ $\left(\left[{ }^{*}\right] P<0.05\right.$, Chi square). $(B, C)$ Learning curves representing time to platform during training trials for animals trained and tested immediately after context pre-exposure $(B)$ and $24 \mathrm{~h}$ after context pre-exposure (C). Two-way ANOVA (nonrepeated measures) revealed no significant difference across training trials in escape latencies between groups $(P>$ $0.5)$, although a significant effect of trial indicated that mice reduced their escape latencies across trials $(P<0.0001)$. Values represent mean + SEM. 
out of nine trials), failure to escape to the platform due to floating, or demonstration of high anxiety levels. Estradiol treatment had a significant effect on the strategy selection of WT female mice tested $24 \mathrm{~h}$ after training $\left(P<0.05, \chi^{2}=4.00\right.$, Chi square) (Fig. $\left.1 \mathrm{~A}\right)$. One of nine oil-injected WT mice used place strategy, whereas five of nine estradiol-injected WT mice used place strategy. Interestingly, estradiol treatment did not enhance place strategy use in DR/C $/ \mathrm{K} 3 \mathrm{KO}$ female mice $\left(P>0.5, \chi^{2}=0.02\right.$, Chi square) (Fig. 1A). Both oil-injected and estradiol-injected DR/C/K3 KO females were biased toward response strategy. Only two of eight oilinjected and two of nine estradiol-injected $\mathrm{KO}$ mice used place strategy. Learning curves of the latency to find the platform during training trials revealed a significant effect of trial $\left(F_{(8,197)}=\right.$ $10.40, P<0.0001$, nonrepeated measures two-way ANOVA), but not of hormone replacement or genotype $\left(F_{(3,197)}=2.23, P=\right.$ 0.09, nonrepeated measures two-way ANOVA) (Fig. 1C). Together, these results suggest a role for $\mathrm{DR} / \mathrm{C} / \mathrm{K} 3$ in estradiolregulated strategy selection in a time-dependent manner, particularly at the long-term 24 -h time point, following pre-exposure to training and testing context.

To further determine the effect of DR/C/K3 on hippocampus function, we also investigated learning strategy using male mice. Forty-nine (22 WT and $27 \mathrm{DR} / \mathrm{C} / \mathrm{K} 3 \mathrm{KO}$ ) male mice were randomly divided into two groups as described above for females: Animals were pre-exposed to the context of training and testing immediately before training (no delay) and $24 \mathrm{~h}$ before training (24-h delay). Fourteen (seven WT and seven KO) of the 49 males were dropped from the study for failing to reach criterion (four correct out of nine trials) or failing to escape to the platform due to floating. No significant difference of genotype was observed when the male mice were pre-exposed immediately before training and testing $\left(P>0.05, \chi^{2}=3.10\right.$, Chi square) (Fig. 2A). Six of nine WT males used place strategy suggesting a trend toward place strategy use. Three of $11 \mathrm{~K} 3 / \mathrm{DR} / \mathrm{C} \mathrm{KO}$ males used place strategy showing a bias toward response strategy use. However, the preference of one strategy over another was not significantly different between groups. Learning curves of the latency to find the platform during training trials revealed a significant effect of trial $\left(F_{(8,122)}=9.07\right.$, $P<0.0001$, nonrepeated measures two-way ANOVA), but not of genotype $\left(F_{(1,122)}=0.49, P=0.49\right.$, nonrepeated measures twoway ANOVA) (Fig. 2B).

On the other hand, a significant difference in the strategy selection between WT and $\mathrm{K} 3 / \mathrm{DR} / \mathrm{C} \mathrm{KO}$ males emerged when tested $24 \mathrm{~h}$ after context pre-exposure $\left(P<0.05, \chi^{2}=3.87\right.$, Chi square $)$ (Fig. 2A). The K3/DR/C KO mice used place strategy significantly more often than WT mice at the 24-h testing time point. Learning curves of the latency to find the platform during training trials revealed a significant effect of trial $\left(F_{(8,101)}=5.08, P<\right.$ 0.0001 , nonrepeated measures two-way ANOVA), but not of genotype $\left(F_{(1,101)}=0.17, P=0.68\right.$, nonrepeated measures two-way ANOVA) (Fig. 2B). These results are consistent with our previous results that tested long-term contextual fear memory (Alexander et al. 2009) and show that lack of K3/DR/C enhances long-term hippocampus-sensitive place strategy in male mice.

We determined the difference in percentage of $\mathrm{WT}$ and $\mathrm{KO}$ mice $(\% \mathrm{KO}-\% \mathrm{WT})$ from each group $(\mathrm{OVX}+\mathrm{E}$, OVX, and male groups) that showed place strategy at the immediate and 24-h time points (Fig. 2C). OVX female and male mice displayed a similar pattern, with fewer KO mice than WT using place strategy immediately after pre-exposure and more $\mathrm{KO}$ mice than WT using place strategy $24 \mathrm{~h}$ after pre-exposure. On the other hand, E treatment caused the opposing effect (more KO than WT mice chose place strategy immediately and fewer $24 \mathrm{~h}$ after pre-exposure). Together, the data suggest that K3/DR/C differentially affects memory formation in a time-dependent manner, and that effect is dependent on estradiol.
A Males immediate and 24 hours after pre-exposure

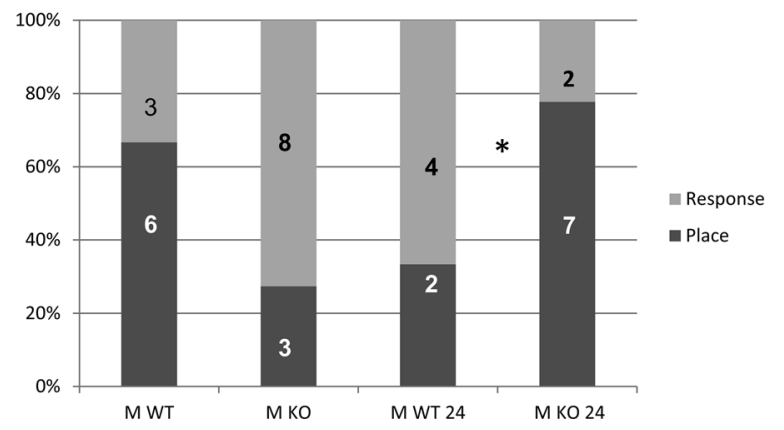

B Latency Curves (Males)
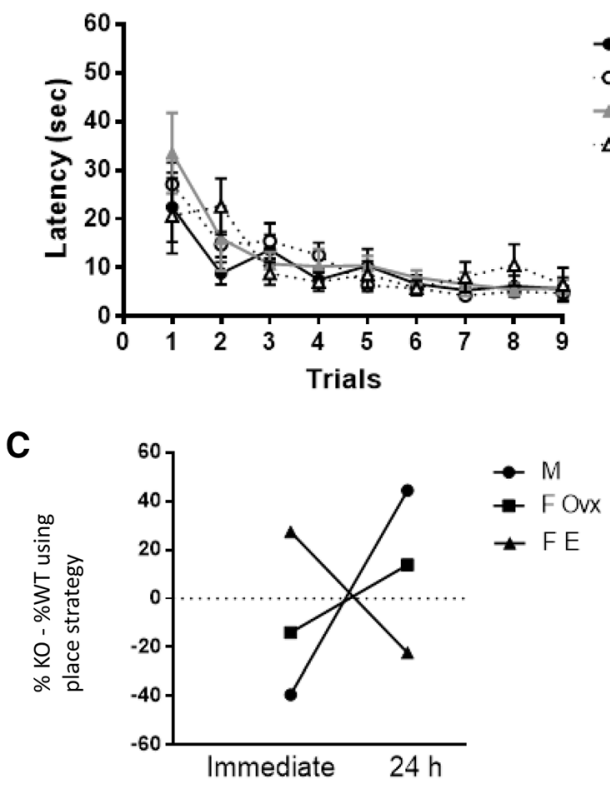

Figure 2. $\mathrm{DR} / \mathrm{C} / \mathrm{K} 3$ inhibits place strategy use in water plus-maze task $24 \mathrm{~h}$ after pre-exposure to training and testing context in male mice. Mice were trained and tested on water plus-maze immediately or $24 \mathrm{~h}$ after the pre-exposure. (A) Bar graph showing the number of WT and DR/C/K3 KO mice that utilized place $\left(\left[{ }^{*}\right] P<0.05\right.$, Chi square) versus response strategies. (B) Learning curves representing time to platform during training trials. Two-way ANOVA (nonrepeated measures) revealed no significant difference across training trials in escape latencies between groups $(P>0.5)$, although a significant effect of trial indicated that mice reduced their escape latencies across trials $(P<0.0001)$. Values represent mean \pm SEM. (C) Difference in percentage of WT mice and KO mice that show place strategy.

To determine whether estradiol affects baseline anxiety levels in these two genotypes, a subset of $\mathrm{WT}$ and $\mathrm{DR} / \mathrm{C} / \mathrm{K} 3 \mathrm{KO}$ females was tested on the elevated plus-maze (EPM) (Fig. 3A) and the open-field (Fig. 3B) tests for anxiety 1 mo after the water plusmaze experiment. Mice were injected with estradiol as before $(48,24$, and $2 \mathrm{~h}$ before testing) and were tested on the third day of injections. Animals with high anxiety levels tend to spend less time in the open arms of the EPM. No significant interaction $\left(F_{(1,28)}=0.25, P=0.62\right)$, effect of hormone $\left(F_{(1,28)}=0.86, P=\right.$ $0.36)$, or effect of genotype $\left(F_{(1,28)}=0.42, P=0.52\right)$ was observed on the time spent in the open arms of the EPM (two-way ANOVA). Similarly, there was no significant interaction $\left(F_{(1,28)}=0.27, P=\right.$ $0.6)$, effect of hormone $\left(F_{(1,28)}=0.15, P=0.7\right)$, or effect of genotype $\left(F_{(1,28)}=0.4, P=0.5\right)$ on time spent in closed arms. In 

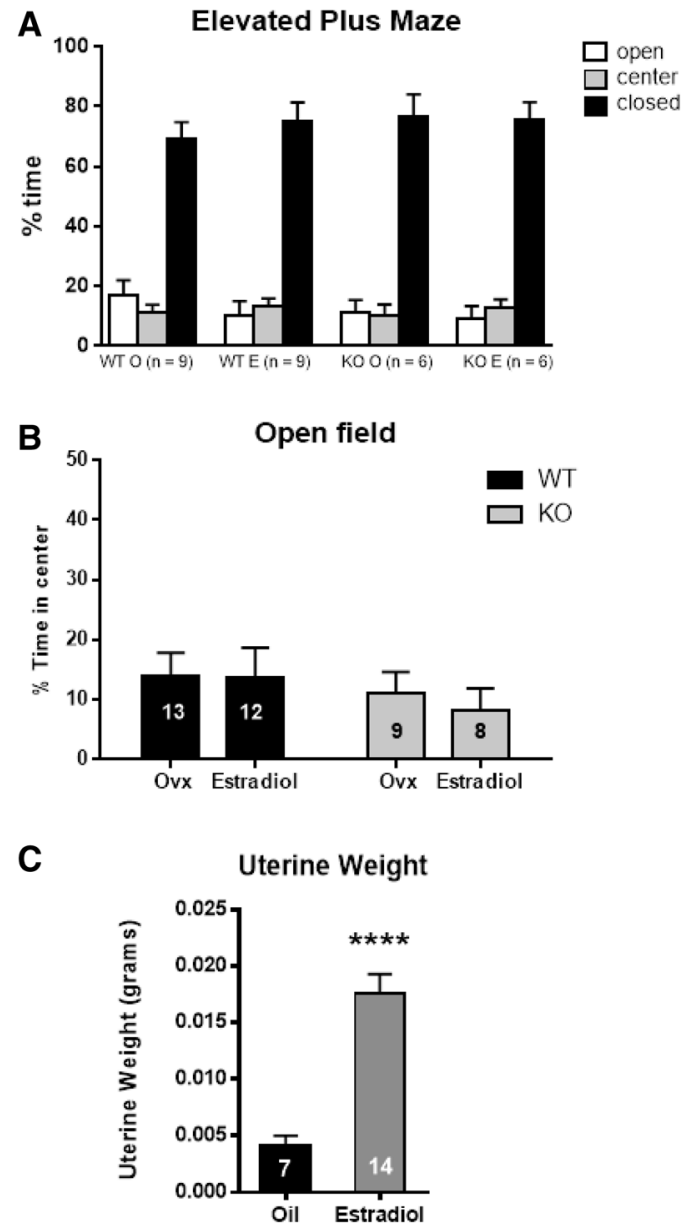

Figure 3. Estradiol had no significant effect on anxiety in WT or DR/C/ K3 KO mice, but it significantly increased uterine weight. WT and KO, sham and estradiol-injected mice were tested on elevated plus-maze $(A)$ and open field $(B)$. No significant effect of genotype or of estradiol injection was observed in the elevated plus-maze or the open field. (C) Estradiol injection significantly increased uterine weight in both WT and KO mice.

addition, another group of mice was tested on the open field (Fig. $3 \mathrm{~B})$. We observed no significant interaction $\left(F_{(1,38)}=0.10, P=\right.$ $0.75)$, effect of ovarian hormones $\left(F_{(1,38)}=0.12, P=0.73\right)$, or effect of genotype $\left.F_{(1,38)}=0.9, P=0.35\right)$ on time spent in the center of the open field. These results indicate that estradiol injections did not have a significant effect on the baseline anxiety levels of either genotype of female mice tested in this study.

Finally, we sacrificed the animals on the third day of injection after the testing and measured their uterine weights to confirm the ovariectomy surgeries and the estradiol injections. There was no significant difference between the uterine weights of WT and KO animals. Therefore, data obtained from these groups were combined for further statistical analysis. Uterine weights of animals which received estradiol injections were significantly higher than those of oil-injected controls $(t=5.2, P<$ $0.0001, t$-test) (Fig. 3C). This measurement is comparable to uterine weights of mice which received the same dose of subcutaneous injections of estradiol in other studies (Kaitu'u-Lino et al. 2007) and of mice on diestrus (Gui et al. 2006). This was expected as we did not choose a dose of estradiol that would mimic proestrus levels of estradiol, since we did not want to get a ceiling effect and possibly lose the difference between WT and $\mathrm{KO}$ animals.

\section{$\mathrm{DR} / \mathrm{C} / \mathrm{K} 3$ and ovarian hormones interact to affect}

\section{fear memory}

Having shown that estradiol administration affects long-term hippocampus function in WT but not $\mathrm{DR} / \mathrm{C} / \mathrm{K} 3 \mathrm{KO}$ mice, and since hormone levels normally fluctuate in a cyclical pattern over the estrous cycle, we also investigated the role of DR/C/K3 and ovarian hormones under physiological conditions in fear memory by testing WT and DR/C/K3 KO female mice, OVX or sham, on contextual and cued fear conditioning (Fig. 4). As an initial investigation, estrous cycle was not monitored in these animals. A two-way ANOVA revealed a significant interaction of surgery and genotype $\left(F_{(1,37)}=4.6, P=0.04\right)$. Further comparison revealed that sham KO froze significantly less than sham WT $(P<0.05)$. Similarly, a significant interaction was also observed in cued fear conditioning $\left(F_{(1,37)}=5.2, P=0.03\right)$; KO sham froze significantly less than WT sham $(P<0.05)$. Differences in the ability to sense the foot shock may affect these results. Foot shock sensitivity was tested at increasing shock intensities in a subset of mice as defined in Materials and Methods (data not shown). Repeated measures ANOVA revealed a trend toward a significant interaction $\left(F_{(18,66)}=1.7, P=0.06\right)$, no significant effect of group $\left(F_{(3,66)}=\right.$ $1.4, P=0.3)$, but a significant effect of intensity $\left(F_{(6,66)}=121.2\right.$, $P<0.0001)$, as expected. It is also important to note that female $\mathrm{KO}$ mice cycle and reproduce normally (unpublished observations), so it does not appear that an explanation for the fear conditioning result is that $\mathrm{DR} / \mathrm{C} / \mathrm{K} 3$ affects estrous cycle. These results suggest that differences in foot shock sensitivity between the groups did not have a significant effect on the results of the
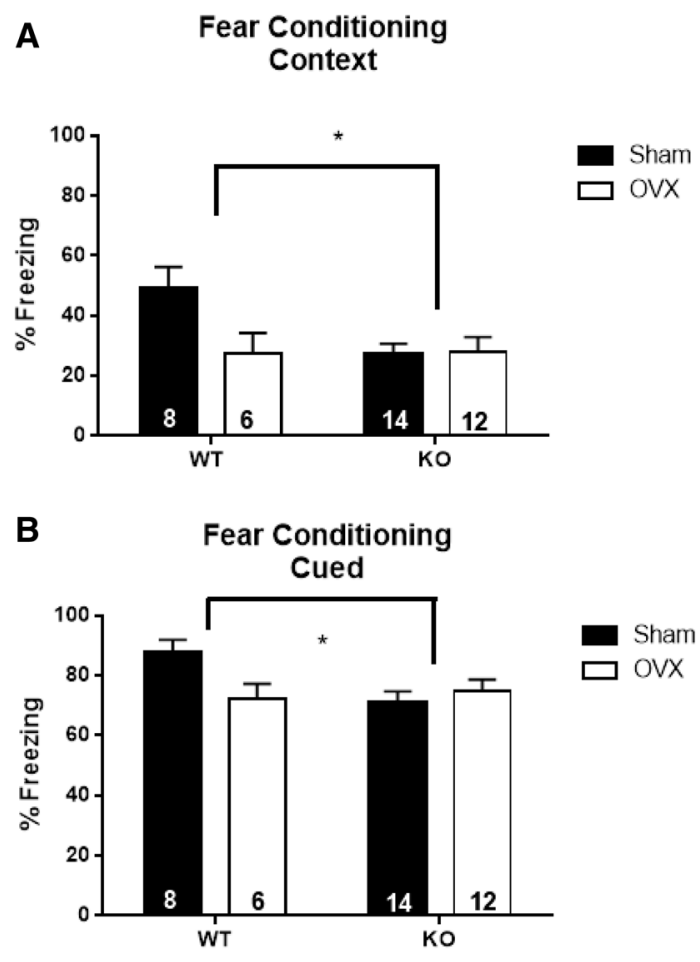

Figure 4. Fear memory is impaired in DR/C/K3 female $\mathrm{KO}$ sham mice. $(A)$ Contextual fear memory was tested $24 \mathrm{~h}$ after training, which consisted of one pairing of cued (white noise) followed by a foot shock ( $1 \mathrm{sec}, 0.5$ $\mathrm{mA}$ ). Freezing to context was reduced $24 \mathrm{~h}$ after training in DR/C/K3 KO mice and by ovariectomy in WT mice, compared to WT sham controls. (B) Freezing to the cue is reduced $48 \mathrm{~h}$ after training in $\mathrm{DR} / \mathrm{C} / \mathrm{K} 3 \mathrm{KO}$ mice and by ovariectomy. In both cases, a significant interaction $\left(\left[^{*}\right] P<0.05\right)$ was observed, such that freezing levels in $\mathrm{DR} / \mathrm{C} / \mathrm{K} 3$ mice were not reduced by OVX. Values represent mean \pm SEM. 
DR/C/K3 modulates estradiol-dependent plasticity

fear conditioning. Overall, this study suggests that DR/C/K3 expression and ovarian hormones interact to affect longterm memory formation in fear conditioning tasks.

\section{Circulating ovarian hormones enhance synaptic plasticity in both WT and DR/C/K3 KO mice}

Since the behavior results suggested a complex interaction between $\mathrm{DR} / \mathrm{C} / \mathrm{K} 3$ and estradiol, a potential cellular mechanism could be through changes in synaptic plasticity in the hippocampus. Male DR/C/K3 KO mice exhibit enhanced synaptic plasticity at the perforant path (PP)-dentate gyrus (DG) and CA3-CA1 synapses (Lilliehook et al. 2003; Fontan-Lozano et al. 2009). We determined the role of $\mathrm{DR} / \mathrm{C} / \mathrm{K} 3$ in synaptic plasticity in female mice in the presence or absence of physiologically fluctuating ovarian hormones. We investigated the effects of OVX on long-term potentiation (LTP) at the PP-DG granule cell synapse in the hippocampus slices from female WT and KO mice. Estrous cycle was tracked, and sham animals were used at proestrus, which has the highest levels of estradiol across the cycle, to further examine the effect of estradiol on synaptic plasticity. Field recordings were acquired from the lower blade of the DG molecular layer and PP inputs were stimulated. Long-term potentiation was induced by thetaburst stimulation (TBS); three trains separated by $20 \mathrm{sec}$, each containing $105-\mathrm{Hz}$ bursts of four $100-\mathrm{Hz}$ pulses) at the PP-DG synapse in hippocampal slices. The average of six field excitatory postsynaptic potentials (fEPSPs) $(1 \mathrm{~min})$ is plotted against time (Fig. 5A). A summary bar graph (Fig. 5B) shows the average of 5 min (30 responses) 40 min after the tetanus (time point labeled B on Fig. 5A). These averages were assessed for group differences. Two-way ANOVA of these data revealed no significant interaction $\left(F_{(1,31)}=1.0, P=0.3\right)$ or effect of genotype $\left(F_{(1,31)}=0.3, P=0.9\right)$, but a significant effect of OVX was revealed $\left(F_{(1,31)}=6.8, P=\right.$ $0.01)$. This result suggests that ovarian hormones significantly enhance LTP in both WT and KO mice. Therefore the effect of ovarian hormones on LTP in the hippocampus slices was independent of DR/C/K3 expression.

\section{DR/C/K3 modulates synaptic physiology}

\section{in female mice}

We further investigated the synaptic physiology in the WT and KO mice. We used paired-pulse depression (PPD) to determine whether neurotransmitter release from the presynaptic terminal is affected by the loss of DR/C/K3 or ovarian hormones. The paired-pulse protocol examines short-term plasticity dependent on presynaptic calcium buildup and vesicular priming and the changes in probability of release of vesicles (Zucker 1989). The medial PP-DG synapse demonstrates PPD (McNaughton 1980; Brown and Reymann 1995), therefore we investigated 50- and 100-msec inter-stimulus intervals (ISI) to confirm proper electrode placement (Fig. 5C,D). Interestingly, two-way ANOVA revealed no significant interaction at 50-msec ISI $\left(F_{(1,41)}=0.07\right.$, $P=0.8)$ or effect of ovariectomy $\left(F_{(1,41)}=2.9, P=0.1\right)$, but a significant effect of genotype $\left(F_{(1,41)}=5.3, P=0.03\right)$ (Fig. 5C).
Similarly at $100-\mathrm{msec}$ ISI, there was no significant interaction $\left(F_{(1,41)}=0.03, P=0.9\right)$ or effect of ovariectomy $\left(F_{(1,41)}=2.9, P=\right.$ $0.09)$, but a significant effect of genotype $\left(F_{(1,41)}=5.6, P=0.02\right)$ (Fig. 5D). These results suggest that although DR/C/K3 expression does not affect LTP induction at the PP-DG synapse in female mice, DR/C/K3 expression does significantly regulate pairedpulse depression and likely release of glutamate from the presynaptic terminal during normal synaptic transmission.

\section{Discussion}

We investigated the role of $\mathrm{DR} / \mathrm{C} / \mathrm{K} 3$ in estradiol modulation of hippocampus-sensitive memory and synaptic plasticity in female mice as well as strategy selection in male and female mice. Studies investigating estradiol's action on learning and memory tasks have resulted in inconsistent data (Korol 2004; Luine 2008), but an overall enhancement of hippocampus-sensitive memory by estradiol is beginning to emerge (Daniel 2006). To further elucidate the effects of estradiol on memory and brain function, researchers have investigated spatial learning strategies. Studies suggest that estradiol enhances hippocampus-sensitive learning strategies, while inhibiting striatum-dependent strategies (Korol and Kolo 2002; Daniel and Lee 2004; Korol et al. 2004; Davis et al. 2005; Tunur et al. 2010). Therefore, we used the water plus-maze task as a tool to investigate the role of DR/C/K3 in strategy use. We previously showed that pre-exposure to the context $30 \mathrm{~min}$ before training and testing enhanced place strategy use in male and intact females, but had no effect in OVX mice (Tunur et al. 2010). Our results from WT male mice were consistent with this previous study (Tunur et al. 2010) in that mice that were pre-exposed to the context with a short delay to training and testing predominantly used place strategy use, whereas a longer delay between preexposure and training and testing did not enhance place strategy use. The mice that lacked DR/C/K3 expression showed enhanced place strategy use at the longer delay. This result is consistent with 
the enhanced contextual fear memory that we previously observed in DR/C/K3 KO mice.

Surprisingly, the estradiol-treated females did not show a strategy preference with a short delay. This is not consistent with the previous study that showed that intact female mice did show enhanced place strategy use with a short pre-exposure delay (Tunur et al. 2010). This may suggest an effect of progesterone or the cyclical nature of the estrous cycle on strategy choice. Interestingly, in the female mice, we found divergent effects of estradiol depending on the delay after pre-exposure to the training and testing context. When animals were trained and tested immediately after pre-exposure, estradiol-injected DR/C/K3 KO mice exhibited enhanced place strategy compared to oil-injected DR/ C/K3 KO mice. Estradiol-injected WT mice did not show significant preference for either strategy. On the other hand, estradiol significantly enhanced place strategy $24 \mathrm{~h}$ after the pre-exposure in WT mice, but had no effect in the KO mice, suggesting that estradiol enhanced long-term contextual memory in the WT, but not in the KO mice. Interestingly, a previous study suggested that estradiol does not affect place strategy per se, but it enhances neurogenesis, which is associated with place strategy use (Rummel et al. 2010), suggesting the mechanism of estradiol may be through enhanced neurogenesis. One caveat here is that the immediate and 24-h groups differed in terms of number of estradiol injections the mice had received at the time of preexposure to training and testing context training. Whereas the immediate group received three injections of estradiol prior to pre-exposure, the 24-h group received only two injections prior to context pre-exposure, although both groups were trained following three injections. This may have also affected the results and an effect of duration of estradiol treatment on pre-exposure cannot be ruled out; however, the effect of DR/C/K3 expression remains, that $\mathrm{DR} / \mathrm{C} / \mathrm{K} 3$ expression is important for long-term memory enhancing effects of estradiol.

To further investigate the effect of the cyclical estrous cycle on memory formation, we also investigated fear conditioning and found an interaction of genotype and hormone status on both contextual and cued fear conditioning. The effect of hormone status is consistent with previous studies that showed estrogen replacement facilitated both cued and contextual fear conditioning in OVX female mice (Jasnow et al. 2006), although other studies suggest opposing effects (Gupta et al. 2001). Our fear conditioning data suggest that DR/C/K3 expression is important for ovarian hormone-modulated long-term fear memory formation. These results are consistent with the strategy selection and suggest that $\mathrm{DR} / \mathrm{C} / \mathrm{K} 3$ is important for long-term estradiol-enhancement of memory. A role for DR/C/K3 and estradiol in regulation of the amygdala function cannot be eliminated, since cued fear conditioning was also reduced in the $\mathrm{KO}$ mice.

\section{Synaptic plasticity and physiology}

To understand the mechanisms of the effects of $\mathrm{DR} / \mathrm{C} / \mathrm{K} 3$ on hippocampus-sensitive learning and memory, we further investigated DR/C/K3's role in synaptic plasticity in the hippocampus in female mice. Field recordings in hippocampal slices revealed a significant effect of hormone status on LTP magnitude, but no effect of genotype. This result is consistent with previous data that showed LTP is enhanced when female rats are in proestrus, a point in the estrous cycle where endogenous estradiol levels are highest (Warren et al. 1995). A similar increase of LTP induction is observed in slices taken from the cycling rat at proestrus (Bi et al. 2001). This effect appears to be mediated by estradiol, as LTP is enhanced in ovariectomized rats treated acutely with estradiol (Cordoba Montoya and Carrer 1997). Significantly, the effects oc- cur rapidly, as bath application of estradiol to hippocampus slices can also enhance the magnitude of LTP (Foy et al. 1999, 2008; Kim et al. 2002; Kramar et al. 2009). These results suggest that estradiol rapidly enhances synaptic transmission and plasticity in the hippocampus, possibly through local synthesis of $17 \beta$-estradiol (Smejkalova and Woolley 2010). In fact, inhibition of aromatase, the final enzyme of local estradiol synthesis, with letrozole, significantly disrupted LTP in slices from female, but not from male rats (Vierk et al. 2012). The lack of effect of DR/C/K3 or interaction of $\mathrm{DR} / \mathrm{C} / \mathrm{K} 3$ expression and ovarian hormones on LTP, however, argues against a role for $\mathrm{DR} / \mathrm{C} / \mathrm{K} 3$ in local synthesis of estradiol or rapid effects of estradiol. Interestingly, a significant effect of genotype, but not of hormone condition, on paired-pulse depression was revealed, suggesting that the synaptic physiology and glutamate release from presynaptic terminals is regulated by DR/C/ $\mathrm{K} 3$. This result is consistent with a presynaptic localization for DR/C/K3 (Zaidi et al. 2002), and the first physiological demonstration of an effect on presynaptic neurotransmitter release by $\mathrm{DR} / \mathrm{C} / \mathrm{K} 3$.

\section{Conclusions}

We and others have shown that DR/C/K3 KO male mice exhibit enhanced performance in hippocampus-sensitive memory tasks, including contextual fear conditioning (Alexander et al. 2009; Fontan-Lozano et al. 2009). In contrast, our results here show that female DR/C/K3 KO mice exhibit reduced long-term cued and contextual fear memory and place strategy selection compared to WT females. Furthermore, estradiol enhanced long-term hippocampus-sensitive spatial memory in WT female mice, but not in DR/C/K3 KO mice. The lack of enhanced long-term memory by ovarian hormones in fear conditioning and estradiol in the water plus-maze experiment in the $\mathrm{KO}$ mice suggests that DR/C/ K3 may be necessary for the estradiol-enhanced memory formation. The previous study in males showed that DR/C/K3 translocates to the nucleus and affects gene transcription during consolidation (Alexander et al. 2009), a process that could affect signaling by the estrogen receptor. The role of estradiol in the male mice is unknown. Indeed, testosterone can be locally aromatized to $17 \beta$-estradiol in the hippocampus, and this aromatization can be activity-dependent (Hojo et al. 2004; Munetsuna et al. 2009). Future experiments will address this possibility by investigation of the molecular mechanisms of the DR/C/K3 and estradiol interaction and the effect of estradiol in WT and KO male mice. We hypothesize that DR/C/K3 may have rapid effects at the membrane, possibly regulating glutamate release, since we observed an effect of DR/C/K3 expression on paired pulse. In addition, DR/C/ K3 may also have long-term effects through transcriptional effects, possibly through an interaction with the ER's role in transcription or other interacting cascade.

Progress in basic understanding of functions of DR/C/K3 and estradiol related to hippocampal plasticity may lead to advancements in combating neurological diseases and conditions involving learning and memory, such as dementia and drug abuse. In addition, elucidation of how DR/C/K3 interacts with these estradiol-mediated processes may provide a more complete understanding of not only DR/C/K3 but also of cognitive roles of estrogens and how to best address hormone-replacement therapies in post-menopausal women.

\section{Materials and Methods}

\section{Generation of KChIP3 knockout mice}

The DR/C/K3 KO mouse line was developed by Dr. Frank An at Lexicon Pharmaceuticals. These animals were generated by targeted disruption of exons $6-8$ of the KChIP3/DREAM/calsenilin 
gene. The line was originally an F1:F1 hybrid between C57BL/ 6c-tyrx129S5/SvEvBrd and back-crossed twice on a 129 background. The mouse colony was maintained using a het $\times$ het breeding scheme and was housed in a controlled environment (temperature $+21^{\circ} \mathrm{C}$; lights, 7:00-19:00 h). Littermate WT and KO virgin female mice 2 to 4 mo old were tested. All protocols followed the guidelines from a protocol approved by the Animal Care and Use Committee of Tulane University in accordance with National Institutes of Health Guide for the Care and Use of Laboratory Animals (1996).

\section{Ovariectomy and estrous cycle determination}

Mice that were tested in fear conditioning and synaptic physiology experiments were ovariectomized or sham-operated. No estradiol was administered in these experiments. Female mice at 3 mo of age were randomly divided into two groups; mice that would receive ovariectomy (OVX) and a sham group. Mice were anesthetized with a ketamine $(80 \mathrm{mg} / \mathrm{kg})$ and xylazine $(8 \mathrm{mg} / \mathrm{kg})$ mixture. The first group of mice received ovariectomy using a dorsolateral approach. The other group of female mice received sham surgery, which consisted of ovary exposure only. Animals were injected with the pain reliever buprenorphine $(5 \mathrm{mg} / \mathrm{kg})$ immediately after the surgery. The cycle of mice tested in the fear conditioning experiments was not determined. The cycle of mice used for the physiology experiments was tracked and mice were sacrificed at proestrus. One week after the surgery, vaginal smears were collected from all females, including OVX as handled controls, at the same time each morning by lavage to track their estrous cycles (Marcondes et al. 2002).

\section{Hormone treatment}

Mice used in the strategy use study were administered estradiol before testing. Ovariectomized $\mathrm{DR} / \mathrm{C} / \mathrm{K} 3 \mathrm{KO}$ and WT mice were randomly assigned to groups receiving subcutaneous injections of either $0.25 \mu \mathrm{g} 17 \beta$-estradiol benzoate (E) dissolved in $100 \mu \mathrm{L}$ sesame oil (E group) or equal volume of sesame oil (vehicle group). All mice received the injections 48,24 , and $2 \mathrm{~h}$ prior to training (Zurkovsky et al. 2007). Uterine weights of animals that received estradiol injections were significantly higher than those of oilinjected controls ( $t=5.2, P<0.0001$, $t$-test) (Fig. 3C), and they are comparable to uterine weights of mice that received same dose of subcutaneous injections of estradiol in other studies (Kaitu'u-Lino et al. 2007) or of mice on diestrus (Gui et al. 2006).

\section{Water plus-maze}

Mice were pre-exposed to context before testing and training. This protocol is adapted from our previous study (Tunur et al. 2010). Immediately or $24 \mathrm{~h}$ before training, mice were pre-exposed for $5 \mathrm{~min}$ to the dry plus-maze in the context of the subsequent training and testing. During the pre-exposure, mice were able to visit three arms of the dry maze. There were visual cues surrounding the maze, on the floor, and on the walls. No extramaze cues were placed directly at the end of any arm. After the pre-exposure, the animal was placed in its home cage. The maze was wiped clean with $70 \%$ ethanol between trials.

Learning strategy was tested on a water plus-maze made of four clear Plexiglas arms (40 cm long, $10 \mathrm{~cm}$ wide, and $40 \mathrm{~cm}$ high) (Tunur et al. 2010). Twenty-four hours after pre-exposure to the training and testing context, the maze was filled to 1.5 $\mathrm{cm}$ above the Plexiglas escape platform $(15 \mathrm{~cm}$ high) with water at room temperature colored opaque with white nontoxic tempera paint. Mice were trained in the water plus-maze task for a training session that consisted of nine trials or six correct choices. Trials were continued for a maximum of $1 \mathrm{~min}$ and separated by an inter-trial interval of $4 \mathrm{~min}$. The animals that made fewer than four correct choices were dropped out of the study. Throughout the training trials one arm (North) was blocked off by a white Plexiglas shield creating a T-shaped maze. Mice were placed in the start arm of the maze (South) and were allowed to swim to the escape platform, which was consistently located in one arm of the maze for each animal and alternated between animals (East or West). Entry into the maze arm that contained the escape platform was scored as a correct response during the training trials, and entry into the maze arm that did not contain the escape platform was scored as an incorrect response. Mice were allowed to remain on the escape platform for $15 \mathrm{sec}$ before being returned to their cages. Mice that failed to find the escape platform within $60 \mathrm{sec}$ were manually guided to the platform. One hour after training, mice were tested on a probe trial to determine their relative use of "place" and "response" learning. On the probe trial, mice were placed into the start arm $180^{\circ}$ opposite the start arm used during training (i.e., end of the North arm) and were allowed to make an entry into either the East or West maze arm. The white Plexiglas shield blocked the South arm during the probe trial. Mice that entered the arm with the platform on the probe trial were designated as using place strategy, and mice that entered the opposite arm on the probe trial were designated as using response strategy.

\section{Elevated plus-maze}

The elevated plus-maze (EPM) consisted of four arms $(5 \mathrm{~cm} \times 30$ $\mathrm{cm}$ ) arranged perpendicularly in a plus shape and elevated 38 $\mathrm{cm}$ above the floor. Two arms were enclosed by $15.5-\mathrm{cm}$ dark Plexiglas walls and two arms were open. A single mouse was placed in the center of the EPM facing a closed arm and allowed to move freely for $5 \mathrm{~min}$. Behavior was monitored by a camera interfaced with a tracking system (US HVS Image). The maze was wiped clean with $70 \%$ ethanol between trials.

\section{Open-field activity}

A single mouse was placed in the center of a white Plexiglas chamber measuring $43 \mathrm{~cm}$ long $\times 43 \mathrm{~cm}$ wide $\times 18 \mathrm{~cm}$ high. The animal explored the novel environment for $15 \mathrm{~min}$ and movements were monitored by a camera interfaced with a tracking system (US HVS Image 2100 Tracking System). The area was divided into 16 virtual squares $(10.75 \times 10.75 \mathrm{~cm})$ by the program, and the middle four squares were defined as the center area. The Plexiglas chamber was wiped clean with $70 \%$ ethanol between trials.

\section{Fear conditioning}

Fear conditioning was performed using a computer-controlled, sound-attenuated conditioning chamber $(29 \times 19 \times 25 \mathrm{~cm}$; Med Associates). On the day of the fear conditioning training, the mouse was exposed to the chamber for the first time and allowed to explore for $150 \mathrm{sec}$. At $150 \mathrm{sec}$ the mouse received one 2-sec electrical foot shock $(0.5 \mathrm{~mA})$ through a stainless steel grid floor. The foot shock was preceded by a 30-sec tone. After the foot shock, the mouse was allowed to explore the context for an additional $150 \mathrm{sec}$. This protocol was used previously for male mice (Alexander et al. 2009). Behavior of the mouse was measured by a digital infrared video camera mounted in front of the chamber.

\section{Context-dependent freezing}

Twenty-four hours after fear conditioning the mouse was returned to the chamber to measure context-dependent fear conditioning. The mouse was placed in the chamber for 300 sec and the percent time freezing was analyzed using Video Freeze Software.

\section{Cued freezing}

Forty-eight hours after initial fear conditioning training mice were returned to the chamber with an altered context. After 150 sec they were exposed to the tone again and the percent time freezing was measured. 


\section{Shock threshold}

Mice were placed in the fear conditioning chamber and allowed to explore for $30 \mathrm{sec}$ before being exposed to a series of foot shocks separated by $30 \mathrm{sec}$. The foot shocks lasted $2 \mathrm{sec}$ and ranged in intensity from 0.1 to $0.7 \mathrm{~mA}$. Shocks were administered in order of ascending intensity. The behavior of the animals was recorded and responses were scored by a blind observer to determine differences in shock sensitivities.

\section{Hippocampus slice preparation}

Female mice were sacrificed at 10-14 wk of age at the proestrus stage of the estrous cycle. Mice were deeply anesthetized under isoflurane anesthesia and their brains were rapidly dissected and placed into ice-cold saline (in mM: 110 sucrose, $60 \mathrm{NaCl}, 3 \mathrm{KCl}$, $1.25 \mathrm{NaH}_{2} \mathrm{PO}_{4}, 28 \mathrm{NaHCO}_{3}, 5 \mathrm{D}$-glucose, $0.5 \mathrm{CaCl}_{2}, 7 \mathrm{MgCl}_{2}$, 0.6 ascorbate). The hippocampi were dissected, and $400-\mu \mathrm{m}$ transverse slices were cut. Slices were transferred immediately into artificial cerebrospinal fluid (ACSF [in mM: $125 \mathrm{NaCl}, 2.5 \mathrm{KCl}$, $1.25 \mathrm{NaH}_{2} \mathrm{PO}_{4}, 25 \mathrm{NaHCO}_{3}, 10 \mathrm{D}$-glucose, $2 \mathrm{CaCl}_{2}, 1 \mathrm{MgCl}_{2}$, saturated with $\left.95 \% \mathrm{O}_{2} / 5 \% \mathrm{CO}_{2}\right]$ ) and maintained at room temperature for $1 \mathrm{~h}$.

\section{Electrophysiology}

Extracellular recordings were performed in an interface chamber continuously perfused at a rate of $1 \mathrm{~mL} / \mathrm{min}$ with $34^{\circ} \mathrm{C}$ ACSF (as described above) saturated with humidified $95 \% \mathrm{O}_{2}$ and $5 \%$ $\mathrm{CO}_{2}$. To stimulate medial perforant path axons, a bipolar tungsten electrode was placed in the lower horn of the dentate gyrus near the insertion point of the entorhinal cortex. A recording electrode was placed in the dendrites of the granule cell layer of the lower horn of the dentate gyrus. Stimulus-response curves were generated by increasing stimulus voltage in $1-\mathrm{V}$ or $0.5-\mathrm{V}$ steps until a maximal response was obtained. Baseline field EPSPs were evoked by delivering $0.1-\mathrm{Hz}$ stimulation at $50 \%$ of maximal input voltage $(2-3 \mathrm{~V})$ for a minimum of $20 \mathrm{~min}$. LTP was induced by delivering a theta-burst stimulation protocol (three trains separated by $20 \mathrm{sec}$, each containing $105-\mathrm{Hz}$ bursts of four $100-\mathrm{Hz}$ pulses) at the same stimulus intensity as baseline transmission. At least $40 \mathrm{~min}$ of fEPSPs were recorded at $0.1 \mathrm{~Hz}$ after theta-burst stimulation. Paired-pulse inhibition at pulse intervals of 100 and $50 \mathrm{msec}$ was measured before theta-burst stimulation to ensure stimulating electrode placement in the medial (versus lateral) perforant path. Data were collected at $4 \mathrm{kHz}$ with an Axopatch 1-D amplifier (Molecular Devices) in current-clamp mode and filtered at $1 \mathrm{kHz}$. Programs were written in National Instruments' LabView controlled stimulation and data collection.

\section{Data analysis}

Two-way ANOVA (surgery $\times$ genotype) was used to analyze fear conditioning and LTP data as described in text. Chi square was used to assess water maze data. Statistics were completed in GraphPad Prism 5.

\section{Acknowledgments}

This work was supported by COBRE grant Mentoring Neuroscience in Louisiana. We thank Frank An for providing KO mice, Dan Liu for technical support, and Jill Daniel and Gary Dohanich for helpful advice.

\section{References}

Alexander JC, McDermott CM, Tunur T, Rands V, Stelly C, Karhson D, Bowlby MR, An WF, Sweatt JD, Schrader LA. 2009. The role of calsenilin/DREAM/KChIP3 in contextual fear conditioning. Learn Mem 16: $167-177$

An WF, Bowlby MR, Betty M, Cao J, Ling HP, Mendoza G, Hinson JW, Mattsson KI, Strassle BW, Trimmer JS, et al. 2000. Modulation of A-type potassium channels by a family of calcium sensors. Nature 403: $553-556$.
Bi R, Foy MR, Vouimba RM, Thompson RF, Baudry M. 2001. Cyclic changes in estradiol regulate synaptic plasticity through the MAP kinase pathway. Proc Natl Acad Sci 98: 13391-13395.

Brown RE, Reymann KG. 1995. Metabotropic glutamate receptor agonists reduce paired-pulse depression in the dentate gyrus of the rat in vitro. Neurosci Lett 196: 17-20.

Buxbaum JD, Choi EK, Luo Y, Lilliehook C, Crowley AC, Merriam DE, Wasco W. 1998. Calsenilin: A calcium-binding protein that interacts with the presenilins and regulates the levels of a presenilin fragment. Nat Med 4: 1177-1181.

Carrion AM, Link WA, Ledo F, Mellstrom B, Naranjo JR. 1999. DREAM is a $\mathrm{Ca}^{2+}$-regulated transcriptional repressor. Nature 398: 80-84.

Cordoba Montoya DA, Carrer HF. 1997. Estrogen facilitates induction of long term potentiation in the hippocampus of awake rats. Brain Res 778: $430-438$.

Daniel JM. 2006. Effects of oestrogen on cognition: What have we learned from basic research? J Neuroendocrinol 18: 787-795.

Daniel JM, Lee CD. 2004. Estrogen replacement in ovariectomized rats affects strategy selection in the Morris water maze. Neurobiol Learn Mem 82: $142-149$.

Davis DM, Jacobson TK, Aliakbari S, Mizumori SJ. 2005. Differential effects of estrogen on hippocampal- and striatal-dependent learning. Neurobiol Learn Mem 84: 132-137.

Fontan-Lozano A, Romero-Granados R, del-Pozo-Martin Y, Suarez-Pereira I, Delgado-Garcia JM, Penninger JM, Carrion AM. 2009. Lack of DREAM protein enhances learning and memory and slows brain aging. Curr Biol 19: $54-60$.

Foy MR, Xu J, Xie X, Brinton RD, Thompson RF, Berger TW. 1999. $17 \beta$-estradiol enhances NMDA receptor-mediated EPSPs and long-term potentiation. J Neurophysiol 81: 925-929.

Foy MR, Baudry M, Diaz Brinton R, Thompson RF. 2008. Estrogen and hippocampal plasticity in rodent models. J Alzheimers Dis 15: $589-603$.

Gold PE. 2004. Coordination of multiple memory systems. Neurobiol Learn Mem 82: 230-242.

Gui Y, Cai Z, Silha JV, Murphy LJ. 2006. Variations in parametrial white adipose tissue mass during the mouse estrous cycle: Relationship with the expression of peroxisome proliferator-activated receptor $-\gamma$ and retinoic acid receptor- $\alpha$. Can J Physiol Pharmacol 84: $887-892$.

Gupta RR, Sen S, Diepenhorst LL, Rudick CN, Maren S. 2001. Estrogen modulates sexually dimorphic contextual fear conditioning and hippocampal long-term potentiation (LTP) in rats. Brain Res 888: 356-365.

Hojo Y, Hattori TA, Enami T, Furukawa A, Suzuki K, Ishii HT, Mukai H, Morrison JH, Janssen WG, Kominami S, et al. 2004. Adult male rat hippocampus synthesizes estradiol from pregnenolone by cytochromes P45017 $\alpha$ and P450 aromatase localized in neurons. Proc Natl Acad Sci 101: $865-870$.

Jasnow AM, Schulkin J, Pfaff DW. 2006. Estrogen facilitates fear conditioning and increases corticotropin-releasing hormone mRNA expression in the central amygdala in female mice. Horm Behav 49: 197-205.

Kaitu'u-Lino TJ, Morison NB, Salamonsen LA. 2007. Estrogen is not essential for full endometrial restoration after breakdown: Lessons from a mouse model. Endocrinology 148: 5105-5111.

Kim JS, Kim HY, Kim JH, Shin HK, Lee SH, Lee YS, Son H. 2002 Enhancement of rat hippocampal long-term potentiation by 17 $\beta$-estradiol involves mitogen-activated protein kinase-dependent and -independent components. Neurosci Lett 332: 65-69.

Korol DL. 2004. Role of estrogen in balancing contributions from multiple memory systems. Neurobiol Learn Mem 82: 309-323.

Korol DL, Kolo LL. 2002. Estrogen-induced changes in place and response learning in young adult female rats. Behav Neurosci 116: 411-420.

Korol DL, Malin EL, Borden KA, Busby RA, Couper-Leo J. 2004. Shifts in preferred learning strategy across the estrous cycle in female rats. Horm Behav 45: 330-338.

Kramar EA, Chen LY, Brandon NJ, Rex CS, Liu F, Gall CM, Lynch G. 2009. Cytoskeletal changes underlie estrogen's acute effects on synaptic transmission and plasticity. I Neurosci 29: 12982-12993.

Lee AS, Duman RS, Pittenger C. 2008. A double dissociation revealing bidirectional competition between striatum and hippocampus during learning. Proc Natl Acad Sci 105: 17163-17168.

Li J, Siegel M, Yuan M, Zeng Z, Finnucan L, Persky R, Hurn PD, McCullough LD. 2011. Estrogen enhances neurogenesis and behavioral recovery after stroke. J Cereb Blood Flow Metab 31: 413-425.

Lilliehook C, Bozdagi O, Yao J, Gomez-Ramirez M, Zaidi NF, Wasco W, Gandy S, Santucci AC, Haroutunian V, Huntley GW, et al. 2003. Altered $\mathrm{A} \beta$ formation and long-term potentiation in a calsenilin knock-out. $J$ Neurosci 23: 9097-9106.

Luine VN. 2008. Sex steroids and cognitive function. J Neuroendocrinol 20: $866-872$. 
Luine VN, Frankfurt M. 2012. Estrogens facilitate memory processing through membrane mediated mechanisms and alterations in spine density. Front Neuroendocrinol 33: 388-402.

Marcondes FK, Bianchi FJ, Tanno AP. 2002. Determination of the estrous cycle phases of rats: Some helpful considerations. Braz J Biol 62: 609-614.

Mazzucco CA, Lieblich SE, Bingham BI, Williamson MA, Viau V, Galea LA. 2006. Both estrogen receptor $\alpha$ and estrogen receptor $\beta$ agonists enhance cell proliferation in the dentate gyrus of adult female rats. Neuroscience 141: 1793-1800.

McNaughton BL. 1980. Evidence for two physiologically distinct perforant pathways to the fascia dentata. Brain Res 199: 1-19.

Mellstrom B, Naranjo JR. 2001. $\mathrm{Ca}^{2+}$-dependent transcriptional repression and derepression: DREAM, a direct effector. Semin Cell Dev Biol 12: 59-63.

Mizumori SJ, Yeshenko O, Gill KM, Davis DM. 2004. Parallel processing across neural systems: Implications for a multiple memory system hypothesis. Neurobiol Learn Mem 82: 278-298.

Munetsuna E, Hojo Y, Hattori M, Ishii H, Kawato S, Ishida A, Kominami SA, Yamazaki T. 2009. Retinoic acid stimulates $17 \beta$-estradiol and testosterone synthesis in rat hippocampal slice cultures. Endocrinology 150: $4260-4269$.

Ormerod BK, Lee TT, Galea LA. 2003. Estradiol initially enhances but subsequently suppresses (via adrenal steroids) granule cell proliferation in the dentate gyrus of adult female rats. J Neurobiol 55: $247-260$.

Packard MG. 1999. Glutamate infused posttraining into the hippocampus or caudate-putamen differentially strengthens place and response learning. Proc Natl Acad Sci 96: 12881-12886.

Packard MG, McGaugh JL. 1996. Inactivation of hippocampus or caudate nucleus with lidocaine differentially affects expression of place and response learning. Neurobiol Learn Mem 65: 65-72.

Rudick CN, Woolley CS. 2001. Estrogen regulates functional inhibition of hippocampal CA1 pyramidal cells in the adult female rat. J Neurosci 21: $6532-6543$.

Rummel J, Epp JR, Galea LA. 2010. Estradiol does not influence strategy choice but place strategy choice is associated with increased cell proliferation in the hippocampus of female rats. Horm Behav 58: 582-590.

Sanz C, Mellstrom B, Link WA, Naranjo JR, Fernandez-Luna JL. 2001. Interleukin 3-dependent activation of DREAM is involved in transcriptional silencing of the apoptotic Hrk gene in hematopoietic progenitor cells. EMBO J 20: 2286-2292.

Savignac M, Pintado B, Gutierrez-Adan A, Palczewska M, Mellstrom B, Naranjo JR. 2005. Transcriptional repressor DREAM regulates
T-lymphocyte proliferation and cytokine gene expression. EMBO J 24: $3555-3564$.

Scsucova S, Palacios D, Savignac M, Mellstrom B, Naranjo JR, Aranda A. 2005. The repressor DREAM acts as a transcriptional activator on Vitamin D and retinoic acid response elements. Nucleic Acids Res 33: $2269-2279$.

Smejkalova T, Woolley CS. 2010. Estradiol acutely potentiates hippocampal excitatory synaptic transmission through a presynaptic mechanism. J Neurosci 30: 16137-16148.

Tunur T, Dohanich GP, Schrader LA. 2010. Pre-exposure to context affects learning strategy selection in mice. Learn Mem 17: 328-331.

Vierk R, Glassmeier G, Zhou L, Brandt N, Fester L, Dudzinski D, Wilkars W, Bender RA, Lewerenz M, Gloger S, et al. 2012. Aromatase inhibition abolishes LTP generation in female but not in male mice. J Neurosci 32: 8116-8126.

Warren SG, Humphreys AG, Juraska JM, Greenough WT. 1995. LTP varies across the estrous cycle: Enhanced synaptic plasticity in proestrus rats. Brain Res 703: 26-30.

White NM, McDonald RJ. 2002. Multiple parallel memory systems in the brain of the rat. Neurobiol Learn Mem 77: 125-184.

Woolley CS, McEwen BS. 1992. Estradiol mediates fluctuation in hippocampal synapse density during the estrous cycle in the adult rat. J Neurosci 12: 2549-2554.

Wu LJ, Mellstrom B, Wang H, Ren M, Domingo S, Kim SS, Li XY, Chen T, Naranjo JR, Zhuo M. 2010. DREAM (downstream regulatory element antagonist modulator) contributes to synaptic depression and contextual fear memory. Mol Brain 3: 3 .

Zaidi NF, Berezovska O, Choi EK, Miller JS, Chan H, Lilliehook C, Hyman BT, Buxbaum JD, Wasco W. 2002. Biochemical and immunocytochemical characterization of calsenilin in mouse brain. Neuroscience 114: 247-263.

Zhang Y, Su P, Liang P, Liu T, Liu X, Liu XY, Zhang B, Han T, Zhu YB, Yin DM, et al. 2010. The DREAM protein negatively regulates the NMDA receptor through interaction with the NR1 subunit. J Neurosci 30: $7575-7586$.

Zucker RS. 1989. Short-term synaptic plasticity. Annu Rev Neurosci 12: $13-31$.

Zurkovsky L, Brown SL, Boyd SE, Fell JA, Korol DL. 2007. Estrogen modulates learning in female rats by acting directly at distinct memory systems. Neuroscience 144: $26-37$.

Received June 19, 2013; accepted in revised form August 25, 2013. 


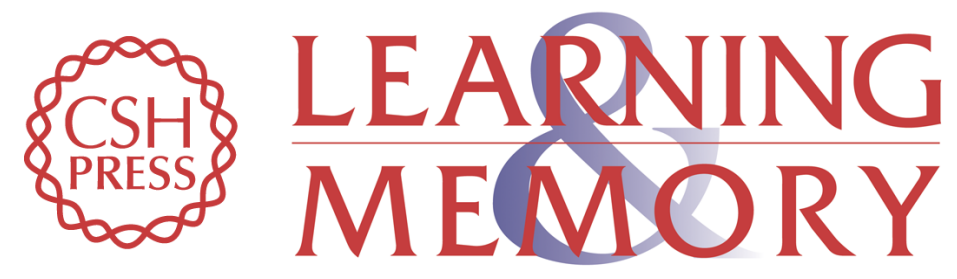

\section{DREAM/calsenilin/KChIP3 modulates strategy selection and estradiol-dependent learning and memory}

Tumay Tunur, Claire E. Stelly and Laura Ann Schrader

Learn. Mem. 2013, 20:

Access the most recent version at doi:10.1101/Im.032052.113

References This article cites 54 articles, 14 of which can be accessed free at: http://learnmem.cshlp.org/content/20/12/686.full.html\#ref-list-1

Creative This article is distributed exclusively by Cold Spring Harbor Laboratory Press for the Commons License first 12 months after the full-issue publication date (see http://learnmem.cshlp.org/site/misc/terms.xhtml). After 12 months, it is available under a Creative Commons License (Attribution-NonCommercial 3.0 Unported), as described at http://creativecommons.org/licenses/by-nc/3.0/.

Email Alerting Receive free email alerts when new articles cite this article - sign up in the box at the Service top right corner of the article or click here. 